Publisher: SPRINGER-VERLAG BERLIN, HEIDELBERGER PLATZ 3, D-14197 BERLIN, GERMANY

Subject Category: Biochemical Research Methods; Chemistry, Analytical

IDS Number: 595MF

ISSN: 1618-2642

DOI: $10.1007 / \mathrm{s} 00216-002-1432-6$

http://www.springerlink.com/content/xb0970dcghrtpt1e/

\title{
SEQUENTIAL SPECTROPHOTOMETRIC DETERMINATION OF METHANOL AND IRON IN VINEGAR BY A FLOW INJECTION- PERVAPORATION METHOD
}

\author{
J. González-Rodríguez ${ }^{1}$, P. Pérez-Juan ${ }^{1}$ and M.D. Luque de Castro ${ }^{2 *}$ \\ ${ }^{1}$ R\&D Department Pérez Barquero, S.A. Avda. de Andalucía, 27, E-14550, \\ Montilla, Córdoba, Spain. Fax: 957 650208, E-mail: barquero@fiab.es \\ ${ }^{2}$ Analytical Chemistry Division, Campus of Rabanales. Annex C-3 Córdoba. Spain. \\ Fax: 34-957-218615, E-mail: qa1lucam@uco.es
}

*Corresponding author

An easily automatable sequential flow-injection-pervaporation method is proposed for the photometric determination of methanol and iron in vinegar. The method is based on separation of the methanol from the sample matrix by pervaporation followed by its oxidation to formaldehyde with permanganate, decolouration of the latter with $\mathrm{S}_{2} \mathrm{O}_{5}^{-2}$ and subsequent reaction of formaldehyde with p-rosaniline to yield a violet reaction product with maximum absorption at $567 \mathrm{~nm}$. Iron is determined by an existing method based on reaction with thiocyanate in acidic medium and monitoring at $508 \mathrm{~nm}$. After optimisation by either the univariate or multivariate approaches, as required, the linear range was established for methanol (4-1000 mg $\mathrm{L}^{-1}$ ) and iron (0.18-20 $\left.\mathrm{mg} \mathrm{L}^{-1}\right)$; The proposed method was then compared with reference methods for methanol and iron in terms of repeatability $\left(2.452 \mathrm{mg} \mathrm{L}^{-1}\right.$ and $0.245 \mathrm{mg} \mathrm{L}^{-1}$, respectively), reproducibility $\left(4.435 \mathrm{mg} \mathrm{L}^{-1}\right.$ and $0.356 \mathrm{mg} \mathrm{L}^{-1}$, respectively), detection limit ( $\mathrm{LOD}=82$ and $0.234 \mathrm{mg} \mathrm{L}^{-1}$, respectively) and traceability. The throughput was nine samples per hour.

Keywords: vinegar, pervaporation, flow injection, spectrophotometry, methanol, iron 


\section{Introduction}

Methanol and iron are two key parameters to be monitored in vinegar. Methanol is always present in vinegar; it is not formed by the acetification process but exclusively by enzymic hydrolysis of the methoxyl groups of pectins during wine fermentation [1]. The methanol content depends on the extent to which solids from grapes, especially the skin, which has a high pectin content, are macerated. Vinegar from red wines has a higher concentration of methanol than white wines. The toxicity of methanol is wellknown -following ingestion, it is oxidized, producing formaldehyde and formic acid, both of which are toxic to the central nervous system. Formaldehyde causes deterioration of the optical nerve, causing blindness. The dangeous levels is $\mathrm{LD}_{50}=350 \mathrm{mg} \mathrm{Kg}^{-1}$ [1]. The presence of iron in vinegars is mainly a result both of contamination by contact with ferrous materials during manufacture, and the iron in the wine from which the vinegar has been made. The iron content, which depend on the matrix, can cause hazes or even serious alteration of appearance and colour as a result of interaction with phenol compounds.

The official method for the analysis of methanol content of vinegar is gas chromatography using a split-type injector and a flame ionisation detector [2]. A usual method consists of oxidation of the analyte to formaldehyde by potassium permanganate in phosphoric medium and spectrophoto- metric monitoring at $575 \mathrm{~nm}$ of the product from the specific reaction of formaldehyde with chromotropic acid [3]. The official method for the determination of iron in vinegar is direct measurement by flame atomic absorption spectrometry (FAAS) [4]; another method is based on reaction with potassium thiocyanate and monitoring of the reaction product at $508 \mathrm{~nm}$. The same procedure is used for wines [5].

No simultaneous, sequential, or individual flow-injection method for determination of both methanol and iron in vinegar has been reported in the analytical literature. Some references can be found on the determination of iron in wines, and some of them use flow injection in an attempt of automation. Neira et al. [6] developed a method for online sample preparation by use of sequential-injection analysis; which was based on complexation of iron with 1,10-phenanthroline and photometric detection at $520 \mathrm{~nm}$. Pulido-Tofino et al. [7] used a fluorescent sensor to determine ironpyoverdin immobilised on controlledpore glass that reacted selectively with $\mathrm{Fe}(\mathrm{III})$, reducing its fluorescence emission. Cladera et al. [8] proposed a method based on the catalytic effect of the iron(III)-ethylenediaminetetracetic acid complex on the oxidation of hydroxylamine by dissolved oxygen with spectrophotometric detection. Only two methods using flow injection for determination of methanol in wine can be found in the analytical literature. One recent method is based on the use of a pervaporation module for the 
separation of methanol and other volatile species from wine before their individual separation and determination by GC-FID [9]. For this purpose, the upper chamber of the pervaporation unit is located in the loop of an HPLC injection valve and the pervaporated species were transported by an $\mathrm{He}$ stream to the chromatograph by changing the valve to the injection position. The other method is based on the use of an alcohol oxidase electrode [10] located in a continuous-flow system.

The aim of this research was the development of a flow-injection method for sequential determination of methanol and iron in vinegar, to enable fast and inexpensive determination. No similar sequential or simultaneous, methods for these species have previously been reported.

\section{Experimental}

\section{Apparatus and instruments}

The manifold used is depicted in Fig. 1.
It was built using two four-channel Gilson Minipuls-3 peristaltic pumps (Villiers le Bel, France) fitted with rate selectors, three Rheodyne 5041 injection valves (Elkay, Galway, Ireland), one of them used as a selecting valve, PTFE tubing of $0.5 \mathrm{~mm}$ i.d. (Análisis Vínicos, Tomelloso, Spain) and a Teflon minicolumn of $5 \mathrm{~mm}$ i.d. and 6 $\mathrm{cm}$ length filled with active carbon. A Cary 50 Conc spectrophotometer from Varian (Mulgrave, Australia) equipped with a Hellma 138-QS flow-cell (Hellma, Jamaica, NY) and connected to a computer with Cary WinUV v.2.0 ${ }^{\circledR}$ (Varian) software for data collection and treatment was also used.

An SBS model TFB-1 Selecta (Barcelona, Spain) thermostat, a laboratory-made pervaporation module, described elsewhere [11-13] and PTFE membranes of $47 \mathrm{~mm}$ diameter and 1,5 $\mathrm{mm}$ thickness (Trace, Braunschweig, Germany) were used. Statistical treatments were made using Statgraphics ${ }^{\mathrm{TM}}$ 2.1 plus for windows.

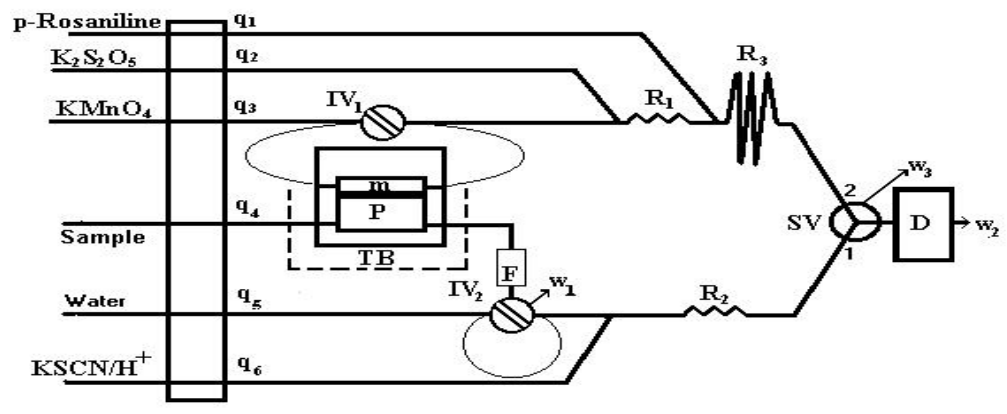

Figure 1. Manifold for the determination of methanol and iron. $\mathrm{PP}=$ peristaltic pump, IV= injection valve, $\mathrm{SV}=$ selecting valve, $\mathrm{R}=$ reactor, $\mathrm{D}=$ detector, $\mathrm{w}=$ waste, $\mathrm{q}=$ flow-rate, $\mathrm{m}=$ membrane, $\mathrm{TB}=$ thermostatic bath, $\mathrm{P}=$ pervaporation module, $\mathrm{F}=$ carbon filter. 
A Varian 3900 Gas-chromatograph with flame ionisation detector (FID) with a Chrompack capillary column CP-wax-57 CB (50 m 0.25 mm i.d.), both from Varian, and connected to a computer with Star chromatography workstation v.5.52 ${ }^{\circledR}$ (Varian) software for data collection and treatment was used to obtain methanol reference data.

A Distillatore Elettronico Enochimico (Gibertini, Milan, Italy) based on water steam dragging was used for methanol distillation.

\section{Reagents and solutions}

Standard solutions for calibration, optimisation and characterisation studies of the methods were prepared from methanol (Merck, Darmstadt, Germany) and iron (III) nitrate (Panreac, Barcelona, Spain).

\section{Proposed method}

The acceptor stream in the pervaporation module was an aqueous solution of $5 \mathrm{~g} \mathrm{~L}^{-1}$ potassium permanganate and $50 \%(\mathrm{v} / \mathrm{v})$ phosphoric acid, both from Panreac. $\mathrm{K}_{2} \mathrm{~S}_{2} \mathrm{O}_{5}$ (Panreac) solution (20 $\mathrm{g} \mathrm{L}^{-1}$ ) was used to decolour surplus permanganate and $0.3 \mathrm{~g} \mathrm{~L}^{-1} \mathrm{p}$-rosaniline (Panreac) solution was also used for methanol determination. Hydrochloric acid (5\% v/v) and potassium thiocyanate solution (45 $\mathrm{g} \mathrm{L}^{-1}$ ), both from Panreac, was used for iron determination. Activated carbon from Aldrich (Steinheim, Germany) was used to decolour the sample before filling the injection valve and a 3\% hydrogen peroxide solution was used for sample pretreatment $\left(\mathrm{Fe}^{+2}\right.$ to $\mathrm{Fe}^{+3}$ transformation).

\section{Reference methods}

Hydrochloric acid (37,5\%), hydrogen peroxide solution (3\%) and potassium thiocyanate solution (200 $\mathrm{g} \mathrm{L}^{-1}$ ), all from Panreac, were used for iron determination. The reference method of methanol used 4-methyl-2-pentanol (Merck) as internal standard; this compound (1110.0 mg, accuracy of 0.1 $\mathrm{mg}$ ) was dissolved in 5\% aqueousethanol and the solution was then diluted to $1 \mathrm{~L}$ in a volumetric flask. The methanol reference solution was prepared by dissolving methanol (50.0 $\mathrm{mg}$, accuracy of $0.1 \mathrm{mg}$ ) in $5 \%$ aqueous ethanol (1L); $1 \mathrm{~mL}$ internal standard solution was added to $10 \mathrm{~mL}$ of the methanol reference solution. $\mathrm{NaOH}$ solution (Panreac; $40 \% \mathrm{~m} / \mathrm{v}$ ) was also used.

\section{Procedures}

\section{Reference method for methanol [2]}

The sample was neutralised with a $40 \%$ $(\mathrm{m} / \mathrm{v})$ sodium hydroxide solution. The internal standard solution $(1 \mathrm{~mL})$ was added to the neutralised sample (10 $\mathrm{mL}$ ) and $1 \mu \mathrm{L}$ of the mixture was injected into the chromatograph. Injector and detector temperatures were $250^{\circ} \mathrm{C}$. The oven temperature was maintained at $50^{\circ} \mathrm{C}$ for $6 \mathrm{~min}$, then programmed at $8^{\circ} \mathrm{C} \min ^{-1}$ to $70^{\circ} \mathrm{C}$, which was held for $14 \mathrm{~min}$, then programmed at $8^{\circ} \mathrm{C} \min ^{-1}$ to $210^{\circ} \mathrm{C}$, which was held for $16 \mathrm{~min}$. The carrier gas flow was $10 \mathrm{~mL} \mathrm{~min}^{-1}$. 
Reference method for iron [5]

Hydrochloric acid $(1 \mathrm{~mL}), \mathrm{H}_{2} \mathrm{O}_{2}$ (5 drops), and potassium thiocyanate (1 $\mathrm{mL}$ ) were added to the sample $(10 \mathrm{~mL})$ and the absorbance was measured at $508 \mathrm{~nm}$. The spectrophotometer was adjusted to zero by using an acidified sample of $10 \mathrm{~mL}$ wine diluted with 1 $\mathrm{mL}$ of distilled water as a blank solution to compensate the influence of the colour of the wine.

Table 1. Results of the optimisation study

\begin{tabular}{lll}
\hline Variable & Tested range & Optimum value \\
\hline Chemical & & \\
$\mathrm{KMnO}_{4}\left(\mathrm{~g} \mathrm{~L}^{-1}\right)$ & $1-20$ & 5 \\
$\mathrm{H}_{3} \mathrm{PO}_{4}(\% \mathrm{v} / \mathrm{v})$ & $1-60$ & 50 \\
$\mathrm{p}^{-R_{0}}$ & $0.1-1$ & 0.3 \\
$\mathrm{~K}_{2} \mathrm{~S}_{2} \mathrm{O}_{5}\left(\mathrm{~g} \mathrm{~L}^{-1}\right)$ & $5-50$ & 20 \\
$\mathrm{KSCN}\left(\mathrm{g} \mathrm{L} \mathrm{L}^{-1}\right)$ & $10-50$ & 45 \\
$\mathrm{HCl}(\% \mathrm{v} / \mathrm{v})$ & $1-15$ & 5 \\
Flow Injection & & \\
$\mathrm{q}_{1}, \mathrm{q}_{2}, \mathrm{q}_{3}=\mathrm{q}_{4}, \mathrm{q}_{5}, \mathrm{q}_{6}\left(\mathrm{~mL} \mathrm{~min}^{-1}\right)$ & $0.4-2.0$ & $0.8 ; 0.6 ; 1.4 ; 1.25 ; 0.4$ \\
$\mathrm{IV} \mathrm{V}_{2}(\mu \mathrm{L})$ & $50-500$ & 300 \\
$\mathrm{R}_{1}, \mathrm{R}_{2}, \mathrm{R}_{3}(\mathrm{~cm})$ & $50-200$ & $75 ; 150 ; 100$ \\
Pervaporation & & \\
$\mathrm{T}\left({ }^{\circ} \mathrm{C}\right)$ & $60-90$ & 85 \\
$\mathrm{t}(\min )$ & $1-8$ & 5 \\
\hline
\end{tabular}

\section{Proposed method}

The sample, previously treated with $\mathrm{H}_{2} \mathrm{O}_{2}$ solution (5 drops), was introduced by aspiration into the dynamic manifold shown in Fig. 1 and pumped into the donor chamber of the pervaporation unit. The methanol was pervaporated and collected in the acceptor solution containing potassium permanganate and phosphoric acid, valve $\mathrm{IV}_{1}$ remaining in the filling position for acceptance of the volatile fraction into a static acceptor solution. At the same time the sample stream leaving the donor chamber was decoloured by passage through an active carbon minicolumn and directed to valve $\mathrm{IV}_{2}$, which was in its filling position. The selecting valve (SV) was in position (1), thus establishing the baseline for the determination of iron. Three minutes after introduction of the sample into the donor chamber, the content of $\mathrm{IV}_{2}$ was injected into an acid stream of potassium thiocyanate and the reaction product monitored at $508 \mathrm{~nm}$. SV was then switched to position (2) to establish the baseline for the determination of methanol. After an interval for sufficient enrichment of the static solution with the pervaporated species 
(5 min from sample introduction), valve $\mathrm{IV}_{1}$ was switched to the injection position and the plug merged with a $\mathrm{K}_{2} \mathrm{~S}_{2} \mathrm{O}_{5}$ stream to decolour the excess of permanganate, and then with a prosaniline stream to yield a violet product which was monitored at 567 $\mathrm{nm}$. An aqueous stream was introduced between analyses in order to clean the donor chamber of the pervaporation unit.

\section{Results and discussion}

Optimisation of the variables affecting each individual method was performed by use of both univariate and multivariate approaches, as required, depending on the interdependence of the variables. The range over which the variables were studied and the optimum values found are given in Table 1 .

\section{Optimisation of the method for the determination of methanol}

\section{Chemical variables}

A multivariate approach was used for optimisation of the concentration of $\mathrm{KMnO}_{4}$ and $\mathrm{H}_{3} \mathrm{PO}_{4}$ within the ranges 1$20 \mathrm{~g} \mathrm{~L}^{-1}$ and $1-60 \%(\mathrm{v} / \mathrm{v})$, respectively; the results obtained are plotted in Fig. 2(a). The signal increased when the concentrations of $\mathrm{H}_{3} \mathrm{PO}_{4}$ and $\mathrm{KMnO}_{4}$ were increased but the former had a greater effect. Concentrations of $5 \mathrm{~g} \mathrm{~L}^{-1}$ potassium permanganate and $50 \%(\mathrm{v} / \mathrm{v})$ phosphoric acid were selected as optimum. Concentrations higher than $60 \%$ phosphoric acid were not tested because of deterioration of the pumping tubes. Because the P-value in the ANOVA table was $<0.01 \%$, there was a statistically significant relationship between the variables at $99 \%$ confidence level. The equation of the fitted model is: $\mathrm{A}=-0.493+0.010\left[\mathrm{KMnO}_{4}\right]+0.030$ $\left[\mathrm{H}_{3} \mathrm{PO}_{4}\right]$. The other chemical variables were studied by use of the univariate method.
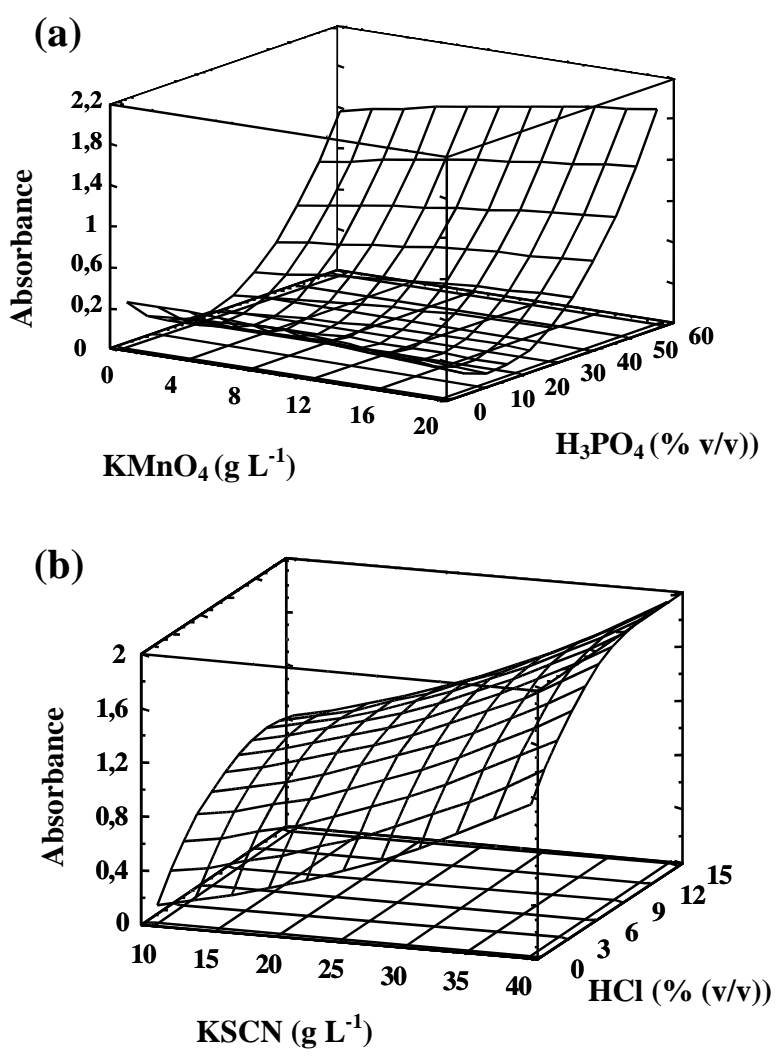

Figure 2. Response surface of the multivariate analysis of: (a) evolution of absorbance versus $\mathrm{KMnO}_{4}\left(\mathrm{~g} \mathrm{~L}^{-1}\right)$ and $\mathrm{H}_{3} \mathrm{PO}_{4}(\%(\mathrm{v} / \mathrm{v}))$ concentrations in the acceptor stream of the pervaporation unit (b) evolution of absorbance versus KSCN $\left(\mathrm{g} \mathrm{L}^{-1}\right)$ and $\mathrm{HCl}(\%(\mathrm{v} / \mathrm{v}))$ concentrations. 
Increasing the concentration of prosaniline increased the analytical signal, which levelled off at prosaniline concentration of $0.3 \mathrm{~g} \mathrm{~L}^{-1}$. The concentration of $\mathrm{K}_{2} \mathrm{~S}_{2} \mathrm{O}_{5}$ used to decolour the acceptor solution before mixing with the p-rosaniline solution was also optimised. A $40 \mathrm{~g} \mathrm{~L}^{-1}$ solution was sufficient for this purpose.

\section{Flow injection and pervaporation variables}

Flow-rates $\mathrm{q}_{3}$ and $\mathrm{q}_{4}$, in Fig. 1 (corresponding to the acceptor and donor stream, respectively, reaching the pervaporator) were set at the same value in order to prevent membrane deformation. A flow-rate of $1.4 \mathrm{~mL}$ $\min ^{-1}$ was selected as a compromise between sensitivity and sampling-rate and the sample was introduced in a continuous way in order to increase sensitivity.

Reactors $R_{1}$ and $R_{3}$ had the function of ensuring proper mixing of the chemical reagents and pervaporated analyte before reaching the spectrophotometer. The length required for this function were 75 and $150 \mathrm{~cm}$, respectively.

Because of the low methanol content of the sample, the efficiency of the pervaporation was favoured by stopping the acceptor solution during this step, thus achieving a higher enrichment by a mass-transfer closer to equilibrium. The pervaporation time, during which the acceptor solution remained static, was tested between 1-8 min; the analytical signal increased as the time was increased, because efficient pervaporation was favoured. A value of $5 \mathrm{~min}$ was chosen as a compromise between sensitivity and sampling rate.

Increasing the temperature had a predictable positive effect on pervaporation and on the analytical signal as a consequence. The signal obtained at $85^{\circ} \mathrm{C}$ was lower than that at $90^{\circ} \mathrm{C}$, but the reproducibility was better $(2.35 \mathrm{mg}$ $\mathrm{L}^{-1}$ at $85^{\circ} \mathrm{C}$ compared with $3.03 \mathrm{mg} \mathrm{L}^{-1}$ at $90^{\circ} \mathrm{C}$ ). For this reason, the temperature of the thermostat was set at $85^{\circ} \mathrm{C}$.

Optimisation of the method for the determination of iron

Preliminary attempts to use a monochannel manifold with the reagent solution acting as the carrier into which the sample was injected resulted in a calibration plot with a narrow linear range, because of the low dispersion of the injected plug into the reagent stream. For this reason, a water stream was used into which the sample, coming from the low chamber of the pervaporation unit, was injected and merged with the potassium thiocyanate solution as shown in Fig 1. Several conditions were optimised using this manifold.

\section{Chemical variables}

The concentrations of both thiocyanate and hydrochloric acid were optimised in the range $10-50 \mathrm{~g} \mathrm{~L}^{-1}$ and $1-15 \%$ $(\mathrm{v} / \mathrm{v})$, respectively, using a multivariate approach. Figure 2(b) shows a plot of the absorbance against both thiocyanate and hydrochloric concentrations. 
Because the P-value in the ANOVA table is less than 0.01, there is a statistically significant relationship between the variables at 99\% confidence level. The equation of the fitted model is: $\mathrm{A}=-0.107+0.045$ $[\mathrm{HCl}]+0.035[\mathrm{KSCN}]$. The optimum values were those providing the highest signal with the lowest reagent consumption.

\section{Flow injection variables}

The length of reactor $R_{2}$ was varied between 50 and $200 \mathrm{~cm}$ and the highest transient peak was obtained when the length was $100 \mathrm{~cm}$, as a result of appropriate mixing of the merged streams with minimum dispersion.

The flow-rates of channels $\mathrm{q}_{5}$ and $\mathrm{q}_{6}$ were tested in the range $0.4-2.0 \mathrm{~mL}$ $\mathrm{min}^{-1}$; the optimum values were 1.25 and $0.4 \mathrm{mLmin}^{-1}$, respectively.

The transient signal provided by the system increased as the injection volume was increased from 50 to 300 $\mu \mathrm{L}$ and then became constant.

\section{Characterisation of the method}

\section{Calibration plots}

In a first stage, five individual standard solutions for each analyte were prepared containing concentrations between 0 and $1000 \mathrm{mg} \mathrm{L}^{-1}$ for methanol and between 0 and $20 \mathrm{mg} \mathrm{L}^{-1}$ for iron. Both sets of solutions were injected in duplicate and the range of linear dependence of response on concentration was found for each analyte. Subsequently new calibration plots were obtained by use of standards containing both analytes. The regression equations were $\mathrm{Y}=0.104 \mathrm{X}+0.009$, $\mathrm{r}^{2}=0.998$ and $\mathrm{Y}=5.5 \times 10^{-3} \mathrm{X}+0.003$, $r^{2}=0.987$ for iron and methanol, respectively.

Different iron-methanol ratios were tested to check for the absence of mutual effects. Iron did not interfere in the determination of methanol, because of the involatile nature of the former, which also ensures its concentration is unaltered during heating the sample in the pervaporation module or filtration through the active carbon micro-column. No statistically significant difference between the results of the individual and joint calibrations.

\section{Assessment of the proposed method}

Thirty different vinegars in different stages of fermentation were used in the assessment study. Each result for methanol or iron content was the average from three determinations and outlier values were deleted by applying the Grubs test [14]. The procedure for assessment consisted of studying analytical parameters such as linear range, traceability by the reference method, repeatability, reproducibility, detection and quantification limits and sample throughput. A robustness study was also developed.

Repeatability ( $r$ ).The F-test was used to establish if the difference between the repeatability of the proposed and reference methods was significant. With this aim, the Fobs $=\mathrm{S}_{\mathrm{r}}{ }^{2}$ $/ \mathrm{S}_{\text {ref }}^{2}$ was compared with the $\mathrm{F}_{1-\alpha}$ obtained from $F$ tables for $\alpha=0.05$ 
( $\mathrm{P}=95 \%)$. As is apparent from Table 2, Fobs $^{\mathrm{r}}$ was always less than $\mathrm{F}_{1-\alpha}$, so the repeatability was similar for the flowinjection and reference method.

Reproducibility $(R)$ (30 days).The

$\mathrm{R}$ values and the results from the applic- ation of the F-test, (Table 2), show that the reproducibility for both FI determinations are statistically equal to those of the reference methods because Fobs $^{\mathrm{R}}<\mathrm{F}_{1-\alpha}$.

Table 2. Analytical characteristics of the proposed method as compared with the reference method

\begin{tabular}{|c|c|c|c|c|}
\hline \multirow{2}{*}{ Characteristic } & \multicolumn{2}{|c|}{ Reference methods } & \multicolumn{2}{|c|}{ FI method } \\
\hline & Iron & Methanol & Iron & Methanol \\
\hline Repeatability $\left(\mathrm{mg} \mathrm{L}^{-1}\right)$ & 0.212 & 1.364 & 0.245 & 2.452 \\
\hline $\mathrm{S}_{\underline{\mathrm{I}}}\left(\mathrm{mg} \mathrm{L}^{-1}\right)$ & 0.078 & 0.433 & 0.097 & 0.580 \\
\hline Reproducibility (mg L ${ }^{-1}$ ) & 0.342 & 2.347 & 0.356 & 4.435 \\
\hline $\mathrm{S}_{\underline{\mathrm{R}}}\left(\mathrm{mg} \mathrm{L}^{-1}\right)$ & 0.084 & 0.675 & 0.108 & 0.897 \\
\hline Fobs $^{\mathrm{r}}$ & & & 1.55 & 1.79 \\
\hline Fobs $^{\mathrm{R}}$ & & & 1.65 & 1.77 \\
\hline $\mathrm{F}_{1-\alpha}(\mathrm{n}=30)$ & 1.84 & & 1.84 & \\
\hline $\mathrm{LOD}\left(\mathrm{mg} \mathrm{L}^{-1}\right)$ & 0.184 & 4 & 0.234 & 82 \\
\hline Sample throughput $\left(\mathrm{h}^{-1}\right)$ & $15^{\mathrm{a}}$ & $3^{a}$ & $9(30)^{\mathrm{b}}$ & \\
\hline
\end{tabular}

$S_{r}$ and $S_{R}$ are the deviations of repeatability and reproducibility, respectively

Fobs $=S^{2} / S_{\text {ref }}^{2}$

${ }^{a}$ In batches of 4 samples

${ }^{\mathrm{b}}$ Individual determination of iron

Detection limits (LOD). In Table 2 the LOD of the reference methods are compared with those of the proposed flow-injection method. For iron the LOD of the reference and flowinjection methods are similar; although this is not true for methanol, the LOD of the proposed method for this analyte is much lower than its usual concentration in vinegars.
Traceability.The traceability of the method was studied by comparing the results obtained from 30 samples of different vinegars analysed by both the reference and proposed methods. Figure 3 shows regression plots of results from the flow injection and reference methods for methanol (a) and iron (b). The regression equations are $\mathrm{y}=0.990 \mathrm{x}$ $+4,986\left(r^{2}=0.991\right)$ and $y=1,05 x-$ 
$0.044\left(r^{2}=0.996\right)$, respectively. Both plots are indicative of good correlation between the data from the proposed method and their reference counterparts. Confidence limits of $95 \%$ are shown in Fig. 3 by dotted lines. For both iron and methanol traceability was assured by use of the t-test.
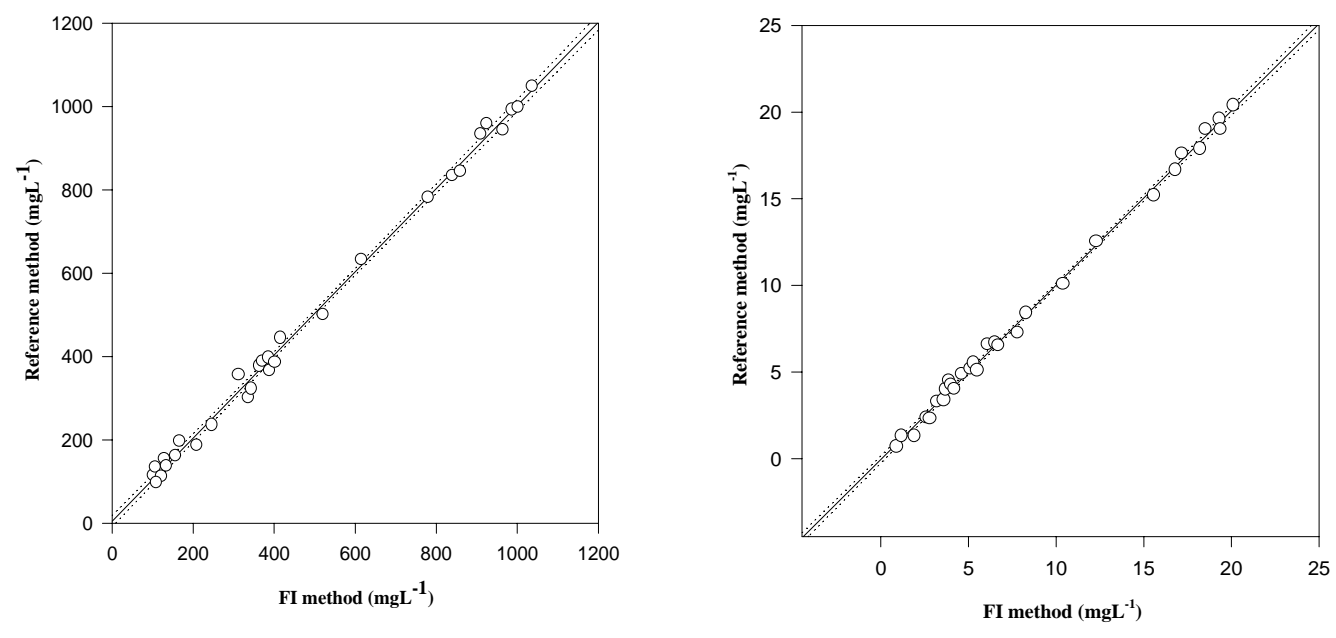

Figure 3. Correlation graph of the reference method with the FI method for (a) methanol and (b) iron. Interval of confidence: $95 \%$.

Sample throughput.The results in Table 2 show that the flow-injection method is higher than that for the reference method for individual determinations. The proposed sequential method (nine determinations per hour) cannot be compared with an official sequential counterpart because of the lack of the latter.

Robustness study. Robustness was studied by use of the the YoundenSteiner procedure [15]. The most significant variables of the system (namely, flow-rate, temperature, pervaporation time and concentrations of potassium permanganate, phosphoric acid, p-rosaniline, potassium pyrosulphite, potassium thiocyanate and hydrochloric acid) were modified by $\pm 10 \%$ from their optimum values. Errors were always less than 10\% except for phosphoric acid, which gave errors of $18 \%$. 


\section{Conclusions}

The proposed method enables sequential determination of iron and methanol in vinegar. The method is simple, presents good correlation with the reference methods and can be easily implemented in a winery for quality control of the final product, thus constituting an alternative to the chromatographic analysis usually required. The method is robust and has a sample throughput higher than that of the reference methods. An additional advantage of the method reported here is its easy automation. This method constitutes a unique sequential application of flow injection for determination in vinegar and offers the advantage of determining two parameters using the same manifold, thus reducing time and costs. This is the first time that a continuous simultaneous method for determining iron and methanol is proposed and assessed for its routine use in wineries.

\section{Acknowledgement}

The Spanish Comisión Interministerial de Ciencia y Tecnología (CICyT) is thanked for financial support (Project BQU 2000/0241).

\section{References}

(1) P Ribereau-Gayon, Y Glories, A Maujean, D Dubourdieu, Handbook of Enology, Volume 2, The Chemistry of Wine. Stabilisation and treatments, (2000) Wiley (Ed.) p. 43.

(2) Resolution OENO 70-2000, Office International de la vigne et du vin (OIV), (1990) Paris

(3)Métodos Oficiales de Análisis. Tomo II, p.396. Ministerio de Agricultura, Pesca y Alimentación. Secretaría General de Alimentación. Dirección General de Política Alimentaria. (1993) Madrid

(4) Resolution OENO 66-2000, Office International de la Vigne et du Vin (OIV), (1990) Paris

(5)J Ribereau-Gayon, E Peinaud, P Sudraud, P Ribereau-Gayon, Tratado de Enología. Ciencias y Técnicas del Vino. Tomo I: Análisis y Control de los Vinos, p. 255, (1980) Hemisferio Sur (Ed.)

(6) JY Neira, N Reyes, JA Nóbrega (2000) Lab. Rob. Autom. 12 (5):246-252

(7) P Pulido-Tofino, JM BarreroMoreno, MC Pérez-Conde (2000) Talanta 51(3):537-545

(8) A Cladera, E Gómez, JM Estela, V Cerdá (1991) Analyst 116 (9):913-917

(9) E Mataix, MD Luque de Castro (2000) Chromatographia 52 (34):205-210

(10) H Belghith, JL Romette, D Thomas (1987) Biotechnol Bioeng 30(9):1001-1005

(11) IL Mattos, MD Luque de Castro (1994) Anal. Chim. Acta 298:159

(12) I Papaesfstathiou, MD Luque de Castro (1995) Anal. Lett. 28:2063 
(13) I Papaesfstathiou, MD Luque de Castro (1995) Anal. Chem. 65:3916

(14) ISO 5725-2:1994(E). Accuracy (trueness and precision) of measurement methods and results. Part 2: Basic method for the determination of repeatability and reproducibility of a standard measurement method, p.12, (1998) ISO (Switzerland)

(15) J. Younden, E.H. Steiner, Statistical Manual of the Association of Official Analytical Chemist (AOAC), AOAC, Washington DC (1975). 